\title{
Analysis of citric æther
}

\section{Malaguti}

To cite this article: M. Malaguti (1837) Analysis of citric æther, Philosophical Magazine Series 3 , 11:64-65, 139-141, DOI: 10.1080/14786443708649240

To link to this article: http://dx.doi.org/10.1080/14786443708649240

册 Published online: 17 Jun 2009.

Submit your article to this journal 준

LII Article views: 2

Q View related articles $₫$ 
contain many documents and much information connected with Newton's life and pursuits that are now highly interesting, and not generally known. The announcement, therefore, that the MSS are now "placed in the hands of an eminent person," with a view to their publication, will be hailed with satisfaction by every friend of science and admirer of Newton, provided they are to be published in an authentic and unmutilated form. But as considerable feeling has already been displayed in connection with this subject, it would be far more satisfactory if the selection were male by a committee of competent persons, acting under the authority of a scientinc body, and not left to the discretion of any individual, however eminent, especially as the original documents are not accessible to those who desire to investigate for themselves. Government, it has been stated, some time ago, expressed a willingness to print them at the public expense. It is greatly to be regretted that this proposal was not agreed to. Controverted points in the bistory of science cannot be set at rest, nor will the reputation of Newton be consultei, by the publication of extracts, however copious and impartially made. The MSS. form a voluminous mass; it is not, therefore, to be expected that they will he printed entire; but, on 1 he other hand, it will be a just subject of national reproach if the correspondence of the most illustrious individual whoever adorned our country is garbled for the purposes of a bookmaking speculation. A. B. - Morn. Chron. June 21, 1837.

Sir Isaac Newton's Manuscripts.-[From a Correspondent.] An erroneous statement having found its way into the newspapers, respect. ing the purchase of Sir Isaac Newton's MSS. by the Royal Society, we are authorized to state that it has nofoundation whatever. In consequence of Sir David Brewster being at present engaged in a large work on the life, writings, and discoveries of Sir Isaac Newton, he was kindly permitted by the trustees of the Earl of Portsmouth to examine the valuable collection of MSS. at Hursbourne Park. With the assistance of H. A. W. Fellowes, Esq., the accomplished nephew of Lord Portsmouth, many interesting and important letters and papers were discovered, which not only throw much new light on the early life and studies of our immortal countryman, but tend to refute the groundless rumours respecting a temporary derangement of his mind in 1692 , and to exalt, in the highest degree, his moral and intellectual character.-Ib. June 27 .

\section{ANALYSIS OF CITRIC ETHER. BY M. MALAGUTI.}

The process recommended to obtain this æther is the following : take 90 parts of crystallized citric acid, 110 of alcohol of sp. gr. 0.814 , and 50 of concentrated sulphuric acid. Put the citric acid, powdered, and alcohol into a tubulated retort, then add the sulphu. ric acid in small portions. Heat the mixture gradually to ebullition, and stop the process, when a very sensible disengagement of sul. phuric æther occurs, which happens when about one third of the volume of the alcohol employed is distilled; the residue is to b e removed from the retort, and twice its volume of distilled water is to be added to it; an oily matter almost instantaneously collects at 
the bottom of the vessel, which is citric æther; it must be repeatedly washed with cold water, and afterwards with a dilute alkaline solution. When the liquid which floats upon the æther leaves no residue on drying, the washing is to be discontinued, and the rether is to be dissolved in alcohol; this solution, which has considerable colour, is to be digested with pure animal charcoal: it is then to be filtered, and the desiccation is to be finished in vacuo. If $8 \frac{6}{10}$ oz. avoirdupoise be employed, the experiment requires only about an hour for its completion, and the product amounts to above $5 \frac{1}{4}$ oz. Pure citric ather is liquid, transparent, of an oily consistence, and a yellowish colour. Its smell somewhat resembles that of olive oil, its taste is bitter and disagreeable, and its density $1 \cdot 142$; it is volatile, but the temperature at which it volatilizes is so near that at which it decomposes, that it cannot be distilled without the decom. position of a large portion of it. If it be heated in an open vessel, it emits a very dense vapour, which inflames on the approach of flame, and a coaly residue is left. In close vessels it begins to lose its limpidity at about $248^{\circ}$ Fahrenheit, becomes reddish at $518^{\circ}$, and begins to boil and to decompose at about $542^{\circ}$; an oily matter being disengaged, afterwards dilute alcohol, lastly carburetted gases and citric ather [acid?]; the residue is charcoal.

Citric æther is perfectly neutral, leaving no residue after combustion; it is soluble in æether, in weak alcohol, and even slightly so in water. An aqueous solution of citric ather becomes acid after some time, and much more quickly so if heated. If citric æther be boiled with a solution of potash or soda, alcohol is obtained, with citrate of the alkali. Solution of ammonia has no immediate action, nor has the dry gas. Neither barytes nor strontian water render either citric ather, or a fresh solution in water, turbid. Nitric acid dissolves it cold, and if the solution be poured into water, the ather does not separate. When the nitric solution is gently heated, a brisk action occurs, which goes on spontaneously; there is a disengagement of red vapours, and the residue has a smell resembling that of hyponitrous acid. If considerable quantities be acted upon, and the ebullition be long continued, oxalic acid is found in the residue; this residue, which is slightly yellow, becomes of a deep red when saturated with ammonia.

Concentrated sulphuric acid immediately imparts colour to citric xther; it dissolves it cold, but quits it on the addition of water, and the ather is unchanged. The sulphuric solution when heated to about $158^{\circ}$, begins to exhibit appearances of a reaction, which becomes extremely strong as the temperature increases; there is a disengagement of alcohol and sulphuric æther, and the residue is red, transparent, very thick, and soluble in water.

Hydrochloric acid dissolves citric æether cold, as the other two acids do, and quits it on the addition of water. The hydrochloric solution does not exhibit any appearance of reaction; the liquid boils, hydrochloric ather is disengaged; a little alcohol, and no citric xther, remain in the residue.

Potassium put in contact with citric æether occasions disengagement of a gas; but the action stops as soon as the surface of the 
metal is oxidized, which very soon occurs; whether this action is occasioned by the decomposition of the ather, or of a little water which it may contain, was not determined.

By analysis this ther yielded, nearly,

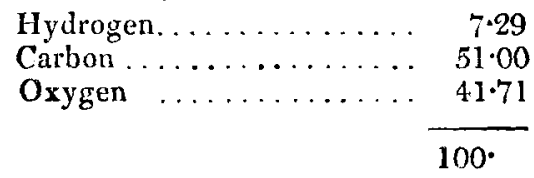

If constituted of an equivalent of citric acid 58 and an equivalent of æther 37 , it would consist of

$$
\begin{aligned}
& \text { Seven equivalents of Hydrogen. . } 7 \text { or } 7.37 \\
& \text { Eight equivalents of Carbon .... } 48 \text {,, } 50.52 \\
& \text { Five equivalents of Oxygen ... } 40,4.2 \cdot 11 \\
& 95100 .
\end{aligned}
$$

This agrees very nearly with Malaguti's analysis, and perfectly with his symbolic representation of its constitution, the weights representing the equivalents varying slightly.

Ann. de Ch. et de Phys, October 1836.

\section{ON THE COMBINATIONS OF AMMONIA WITH ANHYDROUS SALTS.}

M. Rose has examined a considerable number of the compounds which diy ammonia forms with anhydrous salts, volatile metallic chlorides, and oxacids, with the view of ascertaining the general laws to which these combinations are subject.

Their preparation is very simple, but requires time; the ammonia should be passed into a vessel containing caustic potash or lime, and then through a tube filled with caustic potash in small lumps, before it comes in contact with the salt, which is weighed before the operation, the current of ammoniacal gas being continued as long as the salt increases in weight. The combination is usually effected in the cold, and if the substance becomes heated the current of gas must be decreased. The absorption is at first very rapid, but becomes slower by degrees, so much so, that even with those substances which absorb ammonia with avidity, the operation often requires two days. We shall describe the general properties without going into the details of all the compounds examined by M. Rose.

The sulphates of manganese, zinc, copper, nickel, cobalt, cadmium and silver, and the nitrate of the last metal, absorb ammonia; on the contrary, the sulphates of magnesia, nitrates of soda and barytes, phosphate of copper and bichromate of potash do not unite with this alkali. Among the combinations of chlorine with the metals whose oxides are basic, there are many which act with ammonia in a precisely similar manner to the oxacid salts; such are the chlorides of calcium, strontium, copper, nickel, cobalt, lead, silver, the proto- and perchloride of mercury, protochloride of antimony, the perbromide, periodide, and cyanide of mercury. The cyanuret of iron and potassium does not absorb ammonia, 